\title{
JOHN BORDLEY RAWLS: Análise da Antropologia, da Sociedade e da Justiça ${ }^{1}$
}

\author{
Adroaldo Junior Vidal Rodrigues ${ }^{2}$
}

Esperamos que este ensaio de ética em princípio não contenha nada de novo. Quando se trata de questões relativas à vida correta, somente coisas erradas podem ser realmente novas.

Robert Spaemann

\section{RESUMO}

O artigo aborda a Teoria da Justiça do jusfilósofo norte-americano John Bordley Rawls (1921-2002). Dividese em duas etapas: na primeira, é feita uma descrição de sua obra a partir de três elementos: a antropologia, a sociedade e a justiça; na segunda, são apresentadas algumas críticas a cada um desses elementos, utilizando-se da corrente chamada comunitarista, destacando Alasdair MacIntyre, Michael Sandel e Charles Taylor.

Descritores: Teoriada Justiça. John Rawls. Liberalismo. Comunitarismo.

1 Ver também: RODRIGUES, Adroaldo Junior Vidal. Uma introdução à teoria da justiça de John Rawls: análise da antropologia, sociedade e justiça. In: COLÓQUIO SUL-AMERICANO DE REALISMO JURÍDICO, 4.; CONGRESSO SUL-AMERICANO DE FILOSOFIA DO DIREITO, 1., 2005, Porto Alegre, RS. Anais. Porto Alegre: Instituto Jacques Maritain do Rio Grande do Sul, 2005. p. 1-13. 1 CD-ROM.

2 Mestre em Teoria Geral do Direito pela Universidade Federal do Rio Grande do Sul (UFRGS); Professor na Faculdade de Direito do Centro Universitário Ritter dos Reis (UniRitter), e no Curso de Direito das Faculdades Integradas São Judas Tadeu; Membro do Instituto Brasileiro de Filosofia do Direito (IBFD). Currículo: http://buscatextual.cnpq.br/buscatextual/visualizacv.jsp?id=K4770718T5. Endereço profissional: Rua Santos Dumont, 888, Niterói, Canoas, RS, Brasil, CEP 92.120-110 - E-mail: adroaldorodrigues@uniritter.edu.br. 


\section{ABSTRACT}

The article aprouches the Theory of Justice of the professor north american John Bordley Rawls (19212002). It is divided in two stages: first, we will make a description of his work from three elements (Antrophology, Society and Justice); second, we will introduce some critics about each of these elements, using the corrents called comunitaristcs, accentuating Alasdair MacIntyre, Michael Sandel and Charles Taylor.

Descriptors: Theory of Justice. John Rawls. Liberalism. Comunitaristcs.

\section{CONSIDERAÇÕES INICIAIS}

O presente artigo possui como objetivo geral identificar as relações entre a concepção de ser humano, sociedade e justiça de John Rawls, sendo dividido em dois momentos.

Primeiro, verificou-se que a antropologia rawlsiana corresponde ao autointeresse, a sociedade liberal, à neutralidade e a justiça liberal, à imparcialidade.

Para isso, utilizou-se a leitura da obra Uma Teoria da Justiça como principal guia para a extração dos conceitos de Rawls, muito embora, com uma certa frequência, sejam invocadas outras de suas produções, não só para complementar o sentido de seu pensamento, como também para apresentar uma visão geral sobre seus escritos.

Segundo, optou-se por elaborar uma reflexão a partir da seguinte problemática, cristalizada pela interrogação: a teoria da justiça de John Rawls é realmente capaz de constituir uma sociedade justa?

Para testar a viabilidade dessa interrogação invocar-se-á a tese contrária, chamada de comunitarista, que será ilustrada, aqui, por Alasdair MacIntyre, Michael Sandel e Charles Taylor. Por óbvio, um diálogo formar-se-á - o que será benéfico para a ponderação sobre a teoria de Rawls.

Dois são os objetivos específicos: um, expor alguns argumentos presentes nas discussões entre liberais e comunitaristas, tendo em vista a contribuição ao adolescente debate brasileiro sobre esse tema; dois, fomentar estudos em torno da teoria da justiça (que é um tema vinculador das disciplinas de Filosofia do Direito, Filosofia Política e Filosofia

3 Título original: A Theory of Justice. Publicado pela Harvard University Press em 1971. 4 Bobbio explica com objetividade o princípio de utilidade: baseia-se no critério central de que o bom legislador deve criar leis para "a maior felicidade do maior número" (2000, p. 63). 
Moral), contribuindo, assim, para a interdisciplinariedade dos estudos sobre as ciências jurídicas.

A metodologia aplicada é a própria da pesquisa filosófica, qual seja, a análise conceitual.

\section{A TEORIA DA JUSTIÇA DE JOHN RAWLS: análise}

Fazemos, aqui, uma descrição da obra de John Rawls, a partir de três elementos: a antropologia, a sociedade e a justiça.

\subsection{A Antropologia Rawlsiana}

Sem individualismo não há liberalismo. Norberto Bobbio

Os indivíduos, dentro do modelo de sociedade proposto por Rawls, necessariamente, vão buscar os seus interesses. Isso fica evidente quando, nas primeiras páginas da sua teoria da justiça, Rawls considera que: "Se a inclinação dos homens ao interesse próprio torna necessária a vigilância de uns sobre os outros, seu sentido público de justiça torna possível a sua associação segura” (Rawls, 1997, p. 5, grifo nosso).

Assim, o autointeresse torna a justiça necessária e esse sentido de justiça torna-a possível.

A teoria liberal de Rawls não engloba a todos, ou a felicidade do maior número possível, como é para o utilitarismo; ao contrário, prioriza o homem na sua individualidade. Nesse contexto, ainda que haja uma "associação segura” entre os homens, é indubitável que os proveitos buscados individualmente visem a vantagens para si próprios.

O liberalismo rawlsiano é tão dependente dessa concepção de homem "onde os indivíduos buscam os seus fins particulares de modo competitivo" (Barzotto, 2001, p. 141) que, sem ela, a teoria se descaracterizaria completamente. Ou seja, a sociedade liberal e, principalmente, o papel da justiça, que serão tratados mais adiante, seriam mutilados, tendo em vista que somente poderão ser compreendidos a partir de uma linha de raciocínio que se inicia com a compreensão dessa concepção antropológica.

Para John Rawls, ao contrário, o homem é apenas "associal”, isto é, tem sua identidade extraída à margem da sociedade.

Nesse contexto, devem-se considerar dois pontos importantes. O primeiro é que o restante dos homens deve ser ignorado, porque não trariam benefício algum ao "meu” interesse. O outro é que se "eu” me aproximar de alguém, será para usá-lo como meio para atingir o fim que quero.

Diante dessa visão liberal de homem, Norberto Bobbio dispõe que essa possibilidade de eleger valores de per si fomenta a quebra de 
padrões objetivos quando pensa que "esta defesa da autonomia moral do indivíduo provoca uma concepção de relativismo [...]" (Bobbio et al., 1997, p. 701).

Portanto, se as escolhas morais dos indivíduos causam um relativismo, é natural que eles estejam em constante conflito e, por isso, o altruísmo seja substituído pelo seu avesso.

Outra característica igualmente importante da concepção antropológica de Rawls é o modo como o indivíduo é definido dentro da sociedade liberal, a saber, a priori.

$\mathrm{O}$ indivíduo é definido sem levar em conta os bens que elege para sua boa vida. Em outras palavras, é considerado de um modo atomista e possui uma igualdade que é compartilhada de maneira absoluta entre todos os membros que compõem a sociedade.

Para Rawls, o homem é caracterizado de modo alheio à proposta de vida de cada um, ou seja, não há importância se, por exemplo, Pedro é membro de um partido político “x”, possui determinado emprego e família. Os bens que Pedro escolhe para sua vida são infecundos para a formação da identidade liberal. Nesse aspecto, o comunitarista Michael Sandel afirma: "o 'eu' é anterior aos fins que busca" (Sandel, 2000, p. 36).

Na sua teoria, John Rawls é explícito em considerar que o ser humano rompe com a sociedade, tornando-se um ser alheio e, pontuando a diferença entre eles, diz que "a aplicação consistente do princípio da oportunidade equitativa exige que consideremos as pessoas independentemente das influências de sua posição social” (Rawls, 1997, p. 568, grifo nosso).

Assim, existindo conflitos de interesses na sociedade liberal, potencializados por essa concepção de homem já trabalhada, resta fazer uma análise sobre a concepção de sociedade e descobrir como ela é, tendo em vista que uma é a sequência lógica da outra. Nas palavras de Rawls: “Assim sendo, desde o começo, a concepção de pessoa é considerada parte de uma concepção de justiça política e social [...]” (Rawls, 2000, p. 36).

\subsection{A Sociedade Liberal}

A sociedade liberal deve ser concebida como se um mercado fosse, porque a sua antropologia individualista forja um dissenso sobre a concepção de vida boa. A sociedade deve ser neutra para que cada indivíduo busque, de forma competitiva em relação aos outros, os bens que escolheu para a realização da sua concepção particular de vida boa.

Essa ausência de consenso sobre o plano racional de vida reflete em cada pessoa um pluralismo de valores. Nesse sentido, pensa Rawls: “como consequência disso, os indivíduos não 
só têm planos de vida diferentes, mas também existe uma diversidade de crenças filosóficas e religiosas, e de doutrinas políticas e sociais” (Rawls, 1997, p. 138).

Então, o justo para o liberalismo rawlsiano será que a sociedade forneça, de maneira neutra, elementos para que cada cidadão cristalize a felicidade a sua maneira. Sendo a ideia de Rawls que "podemos pensar que a justiça igual significa que a sociedade deve oferecer a mesma contribuição proporcional para que cada pessoa realize o melhor plano de vida que é capaz de formular” (Rawls, 1997, p. 566).

Dado que a sociedade forneça determinados bens de forma igual e imparcial para cada pessoa, "fica obviamente a cargo do próprio agente decidir o que ele mais quer e julgar a importância comparativa de seus vários objetivos” (Rawls, 1997, p. 461).

Nessas circunstâncias, a questão da felicidade e do bem ficam atrelados ao sucesso da realização do plano racional de vida de cada ser humano nessa sociedade. John Rawls os definiu, respectivamente, deste modo: "Um homem é feliz quando é mais ou menos bem-sucedido na maneira de realizar seu plano" (Rawls, 1997, p. 98).

Por óbvio, a sociedade liberal não possui uma finalidade, um bem que lhe é próprio, ao passo que cada cidadão elege para si o que julga ser o melhor para estruturar o seu projeto de vida desejável.
Assim, John Rawls, considerando a globalização, é explícito: “A resposta é que uma sociedade liberal com regime constitucional não tem, como sociedade liberal, uma concepção abrangente do bem. Apenas os cidadãos e associações dentro da sociedade cívica no caso nacional possuem tais concepções" (Rawls, 2001, p. 44, grifo nosso).

Diante disso, surge uma questão inquietante: como os cidadãos vão construir a sua concepção de boa vida, já que cada um pode possuir uma diferente da outra? Rawls, então, utiliza a seguinte ferramenta para poder dar conta desse problema: os chamados bens primários - que visam satisfazer as necessidades mínimas de qualquer projeto de vida.

Logo, esses bens primários contribuem para cada plano racional de vida e para a implementação da felicidade de cada indivíduo. É como se fosse um aparato indispensável para se poder desenvolver qualquer estilo de vida.

E quais são esses bens? Rawls os chama, também, de "valores sociais" e que devem ser distribuídos de forma igualitária entre todos os membros da sociedade liberal. Há duas passagens claras em Uma Teoria da Justiça que abordam essa questão, e uma complementa a outra. A primeira, é quando Rawls diz que: "Para simplificar, suponhamos que os principais bens primários à disposição 
da sociedade sejam direitos, liberdades e oportunidades, renda e riqueza“ (Rawls, 1997, p. 66).

John Rawls destaca, ainda, os "bens naturais" (que ficam à margem do controle pretendido por sua teoria), que são: a saúde e o vigor, a inteligência e a imaginação.

E a segunda passagem do livro (que sublinha um dos bens primários como de vital importância) é: "O fato de a liberdade e a oportunidade, a renda e a riqueza, e, acima de tudo, a auto-estima, serem bens primários deve realmente ser explicado pela teoria restrita” (Rawls, 1997, p. 480).

Com essa visão é difícil haver qualquer perspectiva comunitária e, além disso, essa hipótese é negada por Rawls quando diz literalmente: "Em resposta, dizemos que a justiça como equidade abandona, de fato, o ideal de comunidade política [...]” (Rawls, 2000, p. 250).

\subsection{A Justiça como Imparcialidade}

A justiça liberal é entendida como imparcialidade. E isso ocorre porque a antropologia que a subjaz é apriorística, não sendo definida pela adesão a um bem específico.
Ou seja, é concebida numa ótica de imparcialidade, estabelecendo uma relação de coerência com a sociedade liberal, que é neutra. Assim, é natural que a justiça em Rawls também tenha ideia de neutralidade como núcleo. ${ }^{5}$

Ademais, para registrar de forma explícita esse ponto (em que a justiça liberal é derivada de uma concepção antropológica autointeressada), vejamse as suas palavras: "Podemos supor, portanto, que a mais estável concepção de justiça é aquela que é evidente para o nosso entendimento, congruente com o nosso bem, e fundada não na abnegação, mas na afirmação do eu" (Rawls, 1997, p. 554, grifo nosso).

Essa visão liberal de homem que conduz à concepção de justiça é compartilhada, da mesma forma, pelo professor José Nedel, quando afirma que "Traz no âmago a ideia de imparcialidade, porquanto as partes elegem os princípios através de procedimento imparcial" (Nedel, 2000, p. 55).

Outro aspecto da teoria da justiça de Rawls é a construção do seu fundamento sob a guarda de princípios. No Liberalismo Político, Rawls afirma: "Na justiça como imparcialidade, alguns desses grandes valores - os valores da justiça - são

5 Logo ao abrir o livro Uma Teoria da Justiça, vê-se o nome dado ao primeiro capítulo de "Justiça como Equidade", do original fairness, mas, para fins desse artigo, pensou-se que a melhor tradução seja "imparcialidade". 
expressos pelos princípios de justiça para a estrutura básica - entre eles, os valores de igual liberdade política civil” (Rawls, 2000, p. 185).

Mas como são estabelecidos esses princípios de justiça? Como eles adquirem forma na sociedade liberal? A partir do que Rawls chama de "posição original" e através do contratualismo.

Rawls define a posição original como sendo o status quo inicial apropriado para assegurar que os consensos básicos possam ser concretizados de uma forma equitativa.

Então, essa convenção possui a intenção de iniciar o pensamento e a construção das questões relativas a sua teoria da justiça (entendida de uma forma imparcial).

Já o contratualismo é liame da posição original. Trata-se de uma espécie de reedição do contratualismo de Jean-Jacques Rousseau, Immanuel Kant e John Locke. E Rawls deixa clara tal inspiração quando diz:

Explico: a partir do que dissemos, é claro que a posição original deve ser considerada um artifício de representação e, por conseguinte todo acordo estabelecido pelas partes deve ser visto como hipotético e a-histórico (Rawls, 2000, p. 67).

No entanto, para que esse acordo social seja feito de forma a conduzir a uma justiça imparcial, é necessário que os participantes estejam num pé de igualdade; isso quer dizer que se deve excluir desde as desigualdades sociais aos dons naturais. Observa Rawls, sobre a situação em questão, que a efetividade da posição original deve situar os participantes num ponto de partida igual.

Entra aí o véu de ignorância, que tem a finalidade de "congelar" as pessoas numa situação de igualdade. Nas palavras do próprio Rawls:

E o que chamei de "véu de ignorância" significa que as partes não conhecem a posição social, ou a concepção do bem (seus objetivos e vínculos particulares), ou as capacidades e propensões psicológicas realizadas, e muito mais, das pessoas que representam (Rawls, 2000, p. 359).

Postos os cidadãos num âmbito de igualdade, cabe agora extrair os princípios. Só que esses princípios são buscados através de uma norma chamada de maximim, que consiste em não colher a pior proposta entre as melhores, mas a melhor entre as piores. Rawls põe nestes termos:

A regra maximim determina que classifiquemos as alternativas em vista de seu pior resultado possível: devemos adotar a alternativa cujo pior resultado seja superior aos piores resultados das outras (Rawls, 1997, p. 165).

Depois de passar por várias etapas, há, por fim, os princípios que vão 
estabelecer a justiça imparcial. Mais do que isso, vão permear a vida de cada indivíduo, já que será a principal (senão a única) observação que deve ser respeitada.

São dois os princípios da justiça, sendo o segundo dividido em duas partes. O primeiro diz que cada indivíduo deve ter direito a uma igual liberdade básica ou que "cada pessoa deve ter um direito igual ao mais abrangente sistema total de liberdades básicas iguais que seja compatível com um sistema semelhante de liberdades para todos” (Rawls, 1997, p. 333). O segundo prevê que as desigualdades sociais e econômicas devem satisfazer duas condições: que traga o maior benefício possível para os menos favorecidos, e que "sejam vinculadas a cargos e posições abertos a todos em condições de igualdade equitativa de oportunidades” (Rawls, 1997, p. 333).

Igualmente importante para a aplicação dos princípios é a obediência à ordem léxica, ou seja, ao fato de que o primeiro princípio possui superioridade em relação ao segundo e a primeira condição do segundo tem prevalência.

Esse é, enfim, o conteúdo dos princípios de justiça necessários para uma teoria da justiça liberal.

Cremos que com isto temos as principais passagens das obras de Rawls para cristalizar uma visão unitária de seu pensamento.

\section{A TEORIA DA JUSTIÇA DE JOHN RAWLS: crítica}

Nesta segunda etapa do artigo, apresentamos algumas críticas a cada um desses elementos: a antropologia, a sociedade e a justiça, utilizando-nos da corrente chamada comunitarista.

\subsection{A Antropologia Rawlsiana}

Como se viu antes, para a antropologia liberal rawlsiana o indivíduo é um ser autointeressado, e a justiça somente é invocada para efetivar o interesse de cada um. Vejase como Rawls descreve essa relação do indivíduo com a justiça: "Cada membro da sociedade é visto como possuidor de uma inviolabilidade fundada na justiça, ou, como dizem alguns, no direito natural, que nem mesmo o bem-estar de todos os outros pode anular” (Rawls, 1997, p. 30).

Assim, percebe-se que o interesse de cada pessoa "fundada na justiça”, ou como diria Ronald Dworkin, os “trunfos” que o indivíduo possui e que podem ser invocados contra a sociedade, determinam a exclusão dos interesses de outras pessoas, a partir de uma perspectiva do "meu" em contraposição ao "teu”. Nas palavras de Michael Sandel: "Este supuesto se parece supercialmente a un presupuesto psicológico - estipula que las partes no tienen interes em los intereses de las demás [...]” (Sandel, 2000, p. 77). 
Isso quer dizer que a justiça liberal disponibiliza ao indivíduo uma proteção que tem extensão não só contra outra pessoa que venha a violar seus direitos, como também, contra todos. Ou seja, a própria sociedade. Conforme Sandel, "La justicia tiene primacía sobre los demás valores porque sus princípios se derivan independientemente" (Sandel, 2000, p. 19).

As circunstâncias da justiça podem conduzir a uma total exclusão de valores fraternos e contribuir para a formação de indivíduos egoístas racionais. Eis o que afirma Sandel: “[...] introducen um sesgo individualista, y que rechazan o desvirtúan de alguna manera motivos tales como la benevolência, el altruísmo y los sentimientos comunitários” (Sandel, 2000, p. 84).

Ocorre que nem sempre haverá um ambiente de harmonia. MacIntyre diz: "Naturalmente, ocorre frequentemente que as preferências de indivíduos e de grupos de indivíduos diferentes entram em conflito" (MacIntyre, 1991, p. 367).

Então, o indivíduo posto numa ordem liberal, para saber como deve agir com o intuito de concretizar a sua vida feliz, deve fazer a seguinte pergunta: Qual regra eu devo seguir? Rawls escreveu em Uma Teoria da Justiça sobre a relação entre os princípios e o homem: "Na interpretação contratualista, tratar os homens como fins em si mesmos implica, no mínimo, tratá-los de acordo com os princípios com os quais eles consentiram em uma posição original de igualdade" (Rawls, 1997, p. 195).

Nesse sentido, o raciocínio de MacIntyre é valioso para o entendimento desta questão:

Por conseguinte, na perspectiva moderna, a justificação das virtudes depende de uma justificação anterior das normas e dos princípios; e se estes últimos se tornarem radicalmente problemáticos, como têm se tornado, as primeiras também se tornam (MacIntyre, 2001, p. 206).

Outra reflexão sobre a concepção de homem liberal é no que tange a sua característica de ser tomado a priori. Aquilo que MacIntyre chama de "antropologia de fantasmas", na qual o indivíduo é visto do lado de fora da relação social. E MacIntyre aprofunda esta descrição quando afirma que "Os indivíduos são vistos como possuindo identidade e capacidades humanas essenciais independente e anteriormente à sua participação numa ordem social e política particular” (MacIntyre, 1991, p. 228).

E John Rawls confirma a análise de MacIntyre quando diz que: "Mais ainda, admito que as partes não conhecem as circunstâncias particulares de sua própria sociedade" (Rawls, 1997, p. 147).

No entanto, é inviável que esse tipo de caracterização do indivíduo possa 
alimentar qualquer sociedade, isso porque a identidade humana é dada a partir de uma rede de interações.

Valores comunitários, contrários aos individuais, existem numa sociedade liberal, ainda que se adote essa concepção de indivíduo com fim em si mesmo. Michael Sandel declara sobre essa hipótese:

Probablemente los valores comunitarios existirían, al igual que todos los demás valores que los indivíduos pueden decidir adoptar, e incluso posiblemente florecerían en una sociedad gobernada por los principios de la justicia (Sandel, 2000, p. 85).

Charles Taylor, filosófo comunitarista, assegura que "O puro autointeresse esclarecido nunca moverá um número suficiente de pessoas com força bastante para constituir uma real ameaça a déspotas e putschistas potenciais” (Taylor, 2000, p. 213).

Existe, então, uma identidade social que, quando é ultrajada, por exemplo, é vista de forma clara por todos na forma de uma reação. Taylor comenta sobre isso e exemplifica: "É esse sentido de identidade, e o orgulho que o acompanha, que é ultrajado pelas ações ocultas de um Watergate, e é isso o que provoca a reação irresistível” (Taylor, 2000, p. 212).

Outro argumento diz respeito ao valor do patriotismo. Taylor o define do seguinte modo: "O patriotismo é uma identificação comum com uma comunidade histórica fundada em certos valores” (Taylor, 2000, p. 216).

Esse valor brota, nesse terreno individualista, com a diferença de que ele não é erradicado, pelo contrário, muitas vezes, é superior à própria concepção individual.

Embora Taylor tenha escrito estas palavras antes do exemplo que será dado, não há como negar que serviu como uma luva. É o seguinte: no ataque de 11 de setembro de 2001, em Nova Iorque, se viu, de maneira clara, que um valor comunitário como o patriotismo foi superior a qualquer ato individual. Houve a limitação, inclusive de direitos individuais, o que Rawls afirmou ser ilícito. Assim, o fato não faz com que o argumento esteja errado, mas é um forte indício para a sua revisão.

Outra observação é sobre a relação antropológica e as comunidades que visam ao bem antes do justo. É o caso das comunidades teleológicas, em contraste com as sociedades liberais, que visam ao justo antes do bem, também chamadas deontológicas, e que são negadas por John Rawls. Eis as suas palavras:

Embora, estritamente falando, a subordinação de todos os nossos objetivos a um único objetivo superior não viole os princípios da escolha racional (pelo menos não os princípios de cálculo), ela ainda nos parece irracional ou, mais 
provavelmente, insana (Rawls, 1997, p. 617, grifo nosso).

Talvez os princípios de justiça levem as sociedades liberais a buscar um único bem: o estilo liberal de vida.

\subsection{A Sociedade Liberal}

Não havendo uma concepção compartilhada de vida, a sociedade é vista como um mercado em que os indivíduos interagem de forma competitiva em busca da concretização dos bens que escolheram. John Rawls é explícito ao abordar a questão: “Assim, como notei no início, embora uma sociedade seja um empreendimento cooperativo para a vantagem mútua, ela é tipicamente marcada por um conflito e ao mesmo tempo por uma identidade de interesses" (Rawls, 1997, p.136).

Por conseguinte, essa sociedade liberal "[...] que tenta realizar, no maior grau possível, certos bens ou princípios de direito” (Taylor, 2000, p. 275) não possui um bem que lhe é próprio, a saber, o bem comum.

E o bem comum é o fim de uma comunidade, pois ela nada mais é que o "bem de todos, naquilo que todos temos em comum” (Souza Junior, 2002, p. 29). Mas Rawls nega que a sociedade seja uma comunidade: "Uma sociedade democrática bemordenada não é uma comunidade, nem, em termos mais gerais, uma associação" (Rawls, 2000, p. 84).

Esse raciocínio nos remete a duas características. A primeira é que Rawls reforça a ideia de que a sociedade é entendida como um mercado, já que ela não possui nada em comum a não ser um conjunto de regras que preservam espaço na busca da autonomia dos interesses dos indivíduos. Com outras palavras, a sociedade é montada a partir dos direitos individuais. Taylor comenta sobre isso: "O liberalismo procedimental não pode ter um bem comum no sentido estrito porque a sociedade tem de ser neutra no tocante à questão da vida boa” (Taylor, 2000, p. 210).

A segunda diz respeito à observação feita por Charles Taylor, quando sustenta que a sociedade liberal não é totalmente viável, pois “embora o estado liberal procedimental possa de fato ser neutro diante de (a) crente e não-crentes em Deus, ou de (b) pessoas com orientações homossexual e heterossexual, ele não pode sê-lo entre (c) patriotas e não-patriotas" (Taylor, 2000, p. 214).

$\mathrm{E}$, de fato, não é. Um exemplo disso foi o julgamento do cidadão norte-americano que lutou ao lado dos Talibãs, no Afeganistão. Nesse caso, ignorou-se a suposta neutralidade da sociedade à concepção de vida boa; afirmando-se um estilo coercitivo liberal de vida. 
Outro ponto que pode ser destacado é a questão das sociedades desordenadas, ou que estariam excluídas do modelo de sociedade liberal, descritas por Rawls no segundo capítulo do seu livro O Direito dos Povos, como sendo uma "sociedade onerada por condições desfavoráveis."

Parece que uma sociedade, a qual pode ser considerada, como tantas outras, onerada por condições desfavoráveis, sem dúvida, é o Brasil. Ou seja, o nosso país não serve para a aplicação do projeto liberal.

\subsection{A Justiça como Imparcialidade}

A justiça liberal é uma invocação a normas e princípios para consubstanciar o valor individual. Assim, seu objetivo é saber quais as regras que se devem buscar para uma sociedade justa. O que pressupõe uma concepção de homem autointeressado. É o que afirma Rawls: "Como cada pessoa é livre para planejar a sua vida como quiser (contanto que suas intenções sejam consistentes com os princípios da justiça); não se exige unanimidade sobre os padrões de racionalidade" (Rawls, 1997, p. 495).

A partir disso, abre-se espaço para avaliar se a justiça de John Rawls, entendida como imparcialidade, é consistente.

Uma consideração crítica inicial se refere à falta de retrospecto em relação à posição original. Não existe resposta sobre como se tornou possível esse ponto desencadeador da teoria de Justiça de Rawls. A resposta é constantemente omitida em sua obra e, em consequência, realiza-se a “[...] justiça numa questão de modelos presentes de distribuição para os quais o passado é irrelevante” (MacIntyre, 2001, p. 416, grifo nosso).

Postas as reflexões iniciais, é mister fazer uma observação sobre a aplicação prática da justiça liberal entendida como norma, o que remete aos princípios de justiça.

Usaremos como exemplo o caso dos índios Wanpanoag de Massachusetts, Estados Unidos, descrito por MacIntyre no capítulo XII de seu livro Depois da Virtude. Por meio de uma ação judicial, os índios Wanpanoag reclamaram que suas terras foram ilegal e inconstitucionalmente expropriadas. Detalhe: existe uma cidade em cima delas de nome Mashpee.

Aplicando os princípios de justiça de Rawls, chegar-se-á à conclusão de que o mais próximo de dar uma resposta satisfatória ao problema é o segundo princípio; mais especificamente a sua primeira parte, que possui o seguinte conteúdo: as desigualdades econômicas e sociais devem redundar no maior benefício possível para os membros menos privilegiados da sociedade.

No entanto, o que é justamente necessário saber, nesse caso, é quem 
são os menos privilegiados, pois é sobre eles que o embate se formou.

Aqui há uma fragilidade da justiça liberal rawlsiana, em especial, para identificar os "menos privilegiados". Entretanto, houve uma proposta dada pelos índios Wanpanoag que não foi uma invocação a normas ou princípios. Os indígenas propuseram a seguinte solução - que os selectmem de Masphee se recusaram a aceitar: que todos os terrenos de 4.000 metros quadrados ou menos, nos quais houver uma residência, ficam isentos do processo, frente à decisão favorável de primeiro grau aos reclamantes.

Em outro ponto de sua teoria da justiça, Rawls caracteriza-a como imparcial e exclui dela a ideia de um bem máximo. Isso fica claro quando afirma que: "Embora, estritamente falando, a subordinação de todos os nossos objetivos a um único objetivo superior [...] nos parece irracional ou, mais provavelmente, insano" (Rawls, 1997, p. 617).

No entanto, essa teoria liberal não só não é neutra ou imparcial, como também submete os seus objetivos a "um único objetivo superior”. Eis a crítica de Alasdair MacIntyre: "O supremo bem do liberalismo é a manutenção continuada da ordem social e política liberal, nada mais, nada menos” (MacIntyre, 1991, p. 370).
Curiosamente, a ordem liberal nega, de forma clara, a adesão a uma teoria do bem, mas, ao mesmo tempo, adota uma concepção desse tipo. Nesse sentido, a teoria liberal é contraditória.

Para não deixar dúvidas, MacIntyre aponta ainda que a origem da doutrina liberal, que se propõe a ser impessoal, de fato não o é: "Os pontos de partida da teorização liberal não são nunca neutros no que se refere às concepções do bem humano; eles são sempre pontos de partida liberais” (MacIntyre, 1991, p. 371).

Além do que, se a justiça não visa a um bem, pode conduzir a um mal. Por exemplo, nas atrocidades do Holocausto, nas quais Adolf Eichmann, o burocrata nazista, afirmava que os seus atos eram meros "atos de Estado". ${ }^{6}$

$\mathrm{Na}$ mesma linha de raciocínio, Michael Sandel faz o alerta: "Si um incremento em la justicia no implica necessariamente uma mejora moral incondicional, puede demonstrarse también que em algunos casos, la justicia no es uma virtud sino un vicio" (Sandel, 2000, p. 54, grifo nosso).

O brocardo romano nos lembra que mesmo a justiça deve ter limites: Summum jus, summa injuria.

6 Nesse sentido, ver o capítulo II do livro: ARENDT, Hannah. Eichmann em Jerusalém. São Paulo: Cia. das Letras, 1999. 


\section{CONSIDERAÇÕES FINAIS}

As características expostas por Rawls apresentam problemas que podem comprometer a sua teoria da justiça.

Primeiro, porque, numa linha antropológica, a sua concepção de homem é contaminada por circunstâncias que permitem extrair elementos substantivos de uma natureza humana - o que é constantemente negado, sobretudo quando aponta, por exemplo, como necessária a existência de seres racionais para a sua teoria, o que evita o risco frente à teoria maximim. Além disso, a identidade de cada indivíduo é dada por uma rede de interações que pressupõe o outro, e não o exclui.

Segundo, pois a sociedade liberal não pode ser completamente neutra como se pretendia no projeto original. Vimos que é preciso endossar o patriotismo como aspecto relevante, e os pontos de partida são sempre liberais.

Terceiro, a justiça liberal também não é imparcial, já que possui, como prioridade implícita, a manutenção da ordem liberal.

\section{REFERÊNCIAS}

BARZOTTO, Luis Fernando. Modernidade e democracia: os fundamentos da teoria da democracia de Hans Kelsen. Anuário do Programa de Pós-Graduação em Direito [UNISINOS], São Leopoldo, p. 139-164, 2001.

BOBBIO, Norberto [1909-2004] et al. Dicionário de política. 9. ed. Brasília, DF: UNB, 1997.

MacINTYRE, Alasdair. Depois da virtude. Bauru: EDUSC, 2001.

MacINTYRE, Alasdair. Justiça de quem? Qual racionalidade? São Paulo: Loyola, 1991.

NEDEL, José. A teoria ético-política de John Rawls. Porto Alegre: EDIPUCRS, 2000.
RAWLS, John [1921-2002]. O liberalismo político. Trad. de Dinah Azevedo. São Paulo: Ática, 2000. RAWLS, John [1921-2002]. Uma teoria da justiça. Trad. de Almiro Pisetta e Lenita Esteves. São Paulo: Martins Fontes, 1997. SANDEL, Michael. El liberalismo y los límites de la justicia. Barcelona: GEDISA, 2000.

SOUZA JUNIOR, Cezar Saldanha. A supremacia do direito no estado democrático e seus modelos básicos. Porto Alegre: s.n., 2002. TAYLOR, Charles. Argumentos filosóficos. São Paulo: Loyola, 2000. TAYLOR, Charles. As fontes do self. São Paulo: Loyola, 1997. 


\section{BIBLIOGRAFIA RECOMENDADA}

ARENDT, Hannah. A condição BOBBIO, Norberto [1909-2004]. humana. 10. ed. São Paulo: Locke e o direito natural. 5. ed. Forense Universitária, 2001. Brasília, DF: UNB, 1997.

ARISTÓTELES [384-322aC]. Ética a Nicômaco. São Paulo: Abril Cultural, 1973. (Os Pensadores). ARISTÓTELES [384-322aC]

A política. São Paulo: Nova Cultural, 1999. (Os Pensadores).

BARZOTTO, Luis Fernando. A RAWLS, John [1921-2002]. O direito democracia na Constituição. São Leopoldo: UNISINOS, 2003. dos povos. Trad. de Luís Carlos Borges. São Paulo: Martins BOBBIO, Norberto [1909-2004]. Fontes, 2001.

Liberalismo e democracia. 6. ed. RAWLS, John [1921-2002]. Justicia Trad. Marco Aurélio Nogueira. São Paulo: Brasiliense, 2000. como equidad. Trad. de $\mathrm{M}$. Rodilla. Madrid: Tecnos, 2002. 